\title{
Optical and structural study for DLC thin films prepared by plasma
}

\section{jet}

\section{A. A. Abbass and S. J. Kadhem}

Department of Physics, College of Science, University of Baghdad, Baghdad, Iraq

E-mail: saba_kadhem@yahoo.com

\begin{abstract}
Diamond-like carbon (DLC) homogeneous thin films were deposited from cyclohexane $\left(\mathrm{C}_{6} \mathrm{H}_{12}\right)$ liquid by using a plasma jet system which operates with alternating high voltage $7.5 \mathrm{kv}$ and frequency $28 \mathrm{kHz}$. The optical and structural properties and chemical bonding of these films were investigated. In this work, the effect of changing the distance between the substrate and the plasma torch $(2$, 2.5 and $3 \mathrm{~cm}$ ) was studied. The flow rate of argon gas which used to generate the plasma was fixed $(0.5 \mathrm{~L} / \mathrm{min})$. These films were characterized by UV-Visible spectrophotometer, X-ray diffractometer (XRD) and scanning electron microscopy (SEM) and Fourier transformation infrared spectroscopy (FTIR). The maximum absorption $\left(\lambda_{\max }\right)$ appears around 312, 298.3 and $293.2 \mathrm{~nm}$ at the three distance between plasma torch and the substrate $2.5,2$ and $3 \mathrm{~cm}$, respectively. The values of the optical energy gap are 3.47, 3.65 and $3.76 \mathrm{eV}$ at a different distance $(2,2.5$ and $3 \mathrm{~cm})$, respectively. In XRD diffraction pattern, The occurrence of diamond peaks and graphite peaks in the $\mathrm{x}$-ray spectrum for these films Indicates that there is an occurrence of local ordered $\mathrm{sp}^{3}$ and $\mathrm{sp}^{2}$ for carbon domains and graphite respectively.
\end{abstract}

Key words

Thin films, atmospheric nonthermal plasma jet, carbon nanoparticles, Diamond-Like Carbon (DLC).

Article info.

Received: Sep. 2018

Accepted: Oct. 2018

Published: Mar. 2019

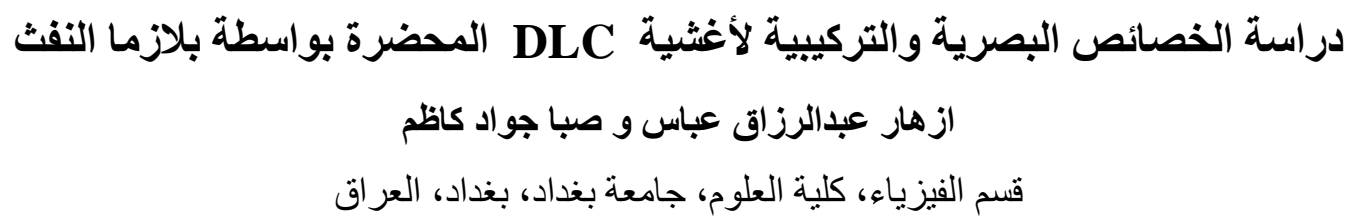

الخلاصة

تم ترسيب أغشية رقيقة متجانسة للكربون شبيه الماس (DLC) العاملة من مركب الهكسان الحلقي (C)

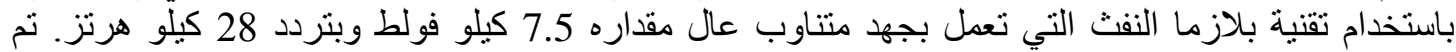

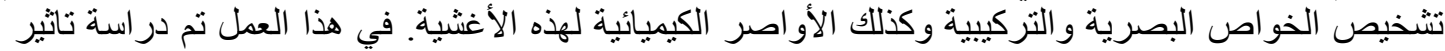

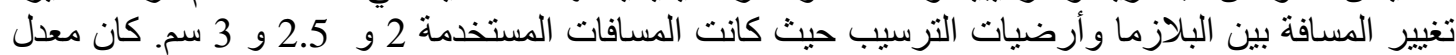

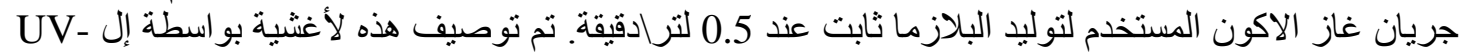
(X-ray diffractometer (XRD) ، absorption spectra Visible

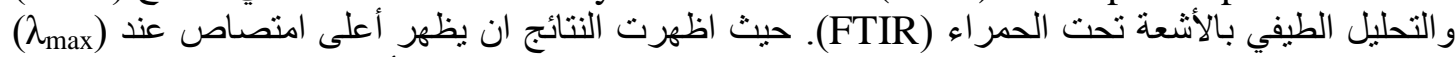

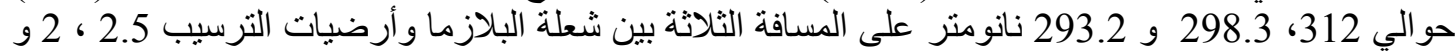

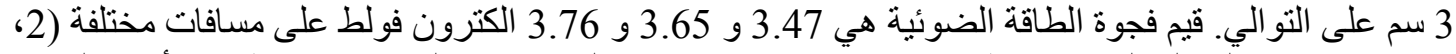

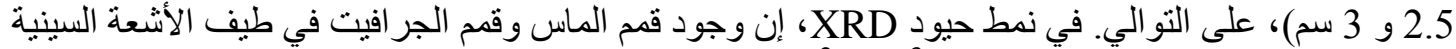

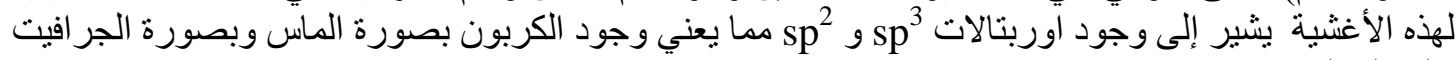

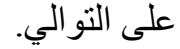




\section{Introduction}

Carbon shows itself in few different phases like diamond [1,2] graphite, fullerenes [3, 4], nanotubes [5-8] and diamond-like carbon [9] because of its ability to hybridize in several structures, for example, tetrahedral $\left(\mathrm{sp}^{3}\right)$, trigonal $\left(\mathrm{sp}^{2}\right)$ and linear coordinations $\left(\mathrm{sp}^{1}\right)$ [10]. Diamond-like carbon (DLC) is an important form of amorphous carbon that consists of a mixture of both $\mathrm{sp}^{3}$ and $\mathrm{sp}^{2}$ coordinated carbon. With a large fraction of $\mathrm{sp}^{3}$ bonded sites, DLC can show properties close to diamond [11]. The properties of this structure include high estimations of hardness, transparency in the infrared range, chemical inertness, low coefficient of friction and high wear resistance.

The plasma jet used in this research is non-thermal works at atmospheric pressure. It is a non-equilibrium system, that's mean the electron temperature is greatly upper than ion temperature [12]. Is an easy design, as it consists of a syringe needle, and it is used as a high voltage electrode. Gas flows through the electrode at many controlled at a various flow rate and could be measured by unit ( $1 / \mathrm{min})$. This system is characterized by high efficiency; the small size of plasma jet enables us to deal with large areas, to give an advantage in dental treatment in medical use, which requires high correctness [12]. Also, it can be used for deposition nitrides, oxides and other materials of thin films [13]. Plasma jets were, in addition, suggested as chemical reactors for decomposition of toxic impurities in the air [14].

In this work, the plasma jet was used to deposit a-C: H nano-thin films.
There are three types of films depending on the sp3 fraction and hydrogen content. These types are polymeric amorphous carbon (PAC), diamond-like carbon (DLC), and graphitic amorphous carbon (GAC) [15].

\section{Experimental part}

Fig. 1. shows the system of plasma jet that used to prepared the DLC thin films on a quartz substrate in our experiment. The torch of plasma jet was generated by using a flow rate of Argon gas $0.5 \mathrm{~L} / \mathrm{min}$ flow through a nebulizer which contained Cyclohexane $\left(\mathrm{C}_{6} \mathrm{H}_{12}\right)$. The mixing of cyclohexane and argon gas was transformed into an aerosol, this aerosol guided by the Argon gas through Teflon tube to the plasma jet. The plasma was ignited by using an electric source at a fixed frequency $(28.0 \mathrm{kHz})$ and high alternated voltage $7.5 \mathrm{kv}$. The deposition system used in this work is shown schematically in fig.1. the distance between the substrate and the plasma torch is variable as 2, 2.5 and $3 \mathrm{~cm}$.

Structural analysis of carbon nanoparticles thin films performed by (Shimadzu XRD-6000 Japan) diffractometer with $\mathrm{CuK}_{\alpha}$ radiation $(\lambda=1.5418 \AA)$ at $40 \mathrm{kV}$ and $30 \mathrm{~mA}$ in the scanning angle $(2 \theta)$ from $20^{\circ}$ to $80^{\circ}$ with the scanning speed of $0.05 \mathrm{deg} / \mathrm{s}$. The surface morphology was examined by scanning electron microscopy (SEM) under ambient condition. The optical transmission spectra of the deposited films were recorded using UV-VIS double-beam spectrophotometer in the wavelength range $200-1100 \mathrm{~nm}$. 


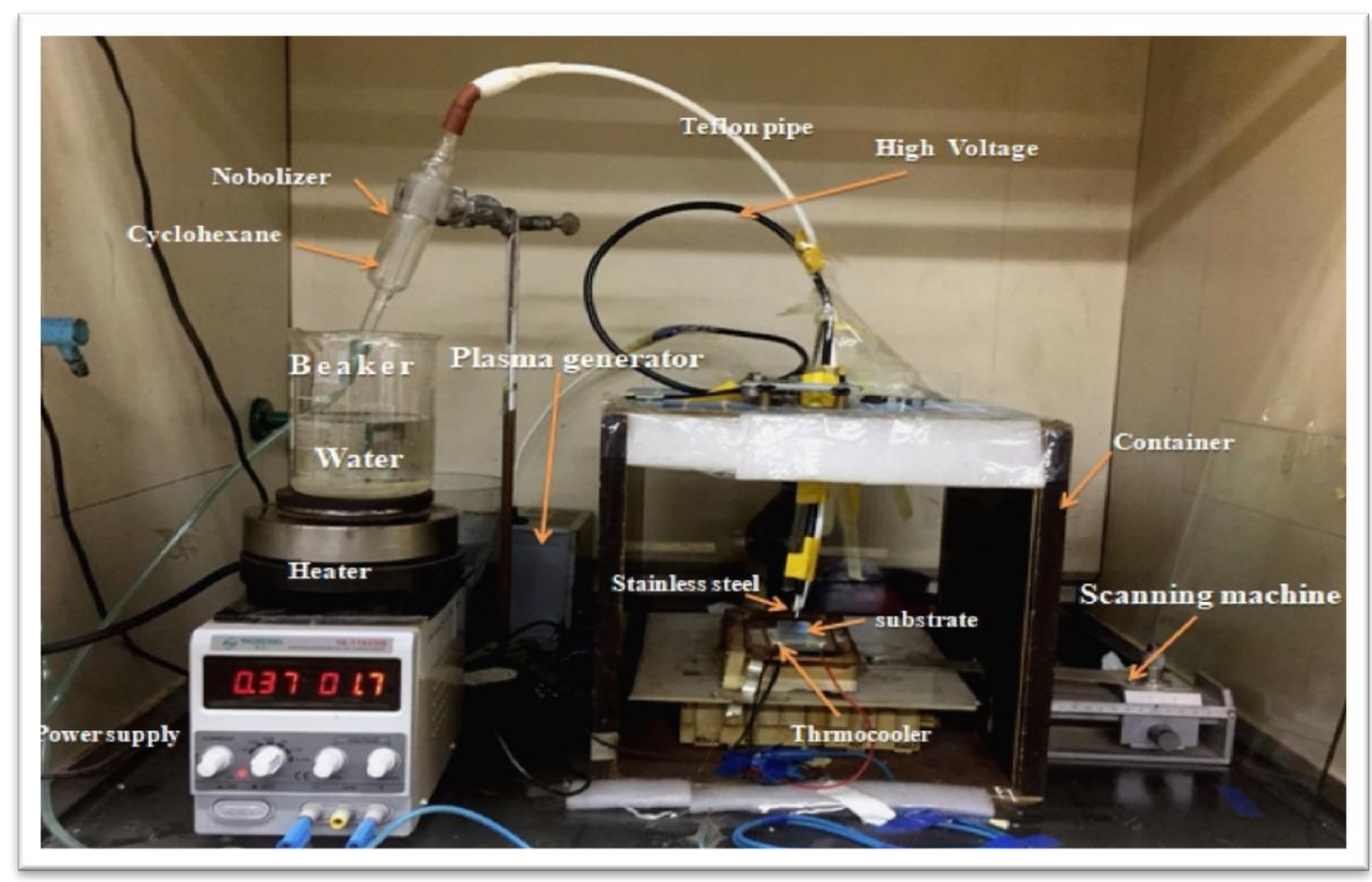

Fig. 1: The plasma jet system used to synthesize the DLC thin films.

\section{Results and discussion \\ Measurements of optical properties}

Fig.2 shows the variation of absorbance spectra as a function of wavelength for these thin films at different distances. The Absorbance of thin films estimating in the UV-Visible at region (300-1100 $\mathrm{nm})$ has been analyzed. Numerous Layers of carbon nanoparticles deposited with $0.5 \mathrm{~L} / \mathrm{min}$ as a fixed flow rate of argon gas on quartz substrates with a thickness 200 , $220,250 \mathrm{~nm}$ at the different distance between the substrate and plasma torch $(2,2.5$ and $3 \mathrm{~cm})$, respectively. The maximum absorption $\left(\lambda_{\max }\right)$ appears around $312,298.3$ and $293.2 \mathrm{~nm}$ at the three distance between the substrate and plasma torch $2.5,2$ and $3 \mathrm{~cm}$, respectively. It can be noticed that all films have a high absorbance at high energies. The highest absorption found for the film which prepared at distance $2.5 \mathrm{~cm}$. The figure shows the peaks width increases when the distance decreases. Because the flow of particles is high when the distance between the plasma nozzle and the substrate is small $(2 \mathrm{~cm})$, which leads to the dispersion of particles, therefore the rate of deposition is small while at the distance is large $(3 \mathrm{~cm})$, the particles flow is very slow so, this also leads to a low deposition rate. The best distance gets the good deposition of particles at distance $2.5 \mathrm{~cm}$. 


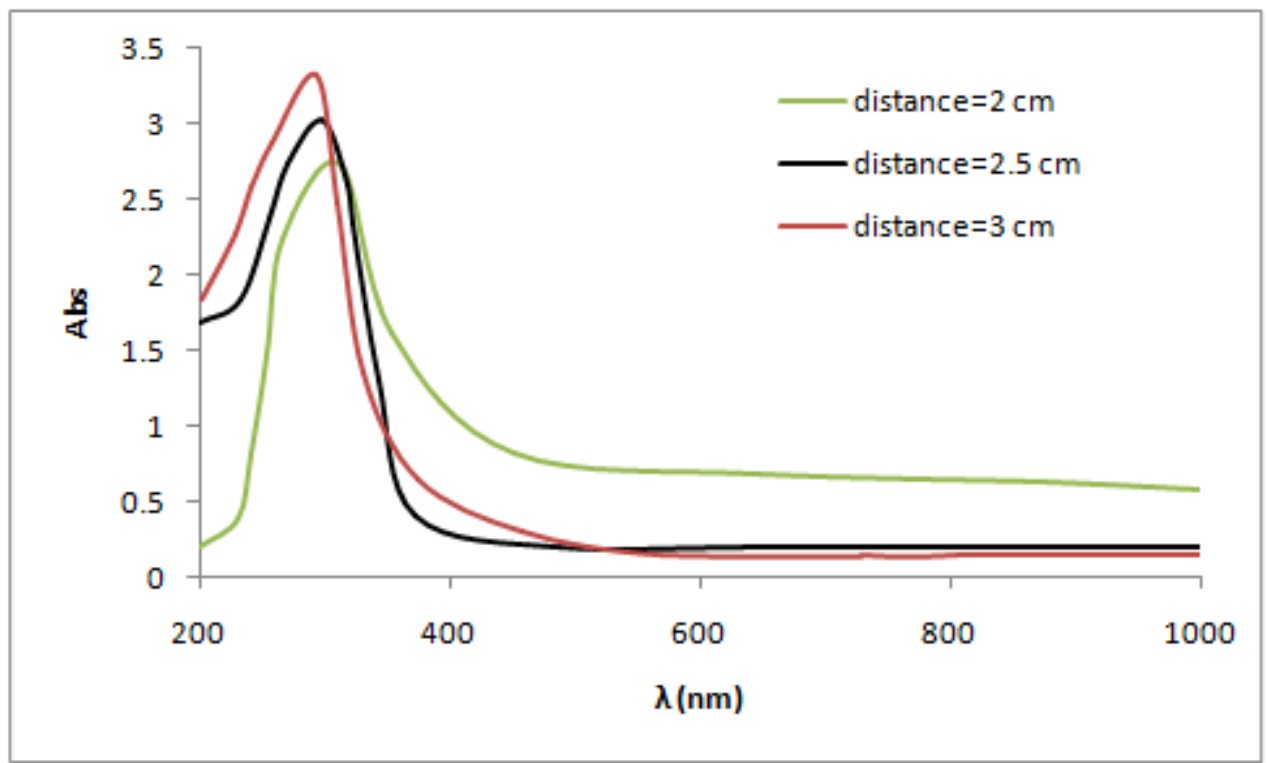

Fig. 2: Absorption spectra for a-C: $H$ thin films thin film at the different distance between the substrate and plasma torch.

The value of the optical energy gap is shown in Fig. 3 at distance $(2,2.5$ and 3$) \mathrm{cm}$ between the substrate and plasma torch are $3.47,3.65$ and $3.76 \mathrm{eV}$, respectively. It can be seen that the highest optical energy gap found at a distance of $2.5 \mathrm{~cm}$. This indicates that this sample contains the highest ratio of the $\mathrm{sp}^{3}$ fraction. The type of transition was directly allowed transition as the dependence of $(\alpha)$ on the photon energy $(h v)$ was found to follow the subsequent relationship [16]:

$\alpha h v=\beta\left(h v-E_{g}\right)^{\frac{1}{2}}$

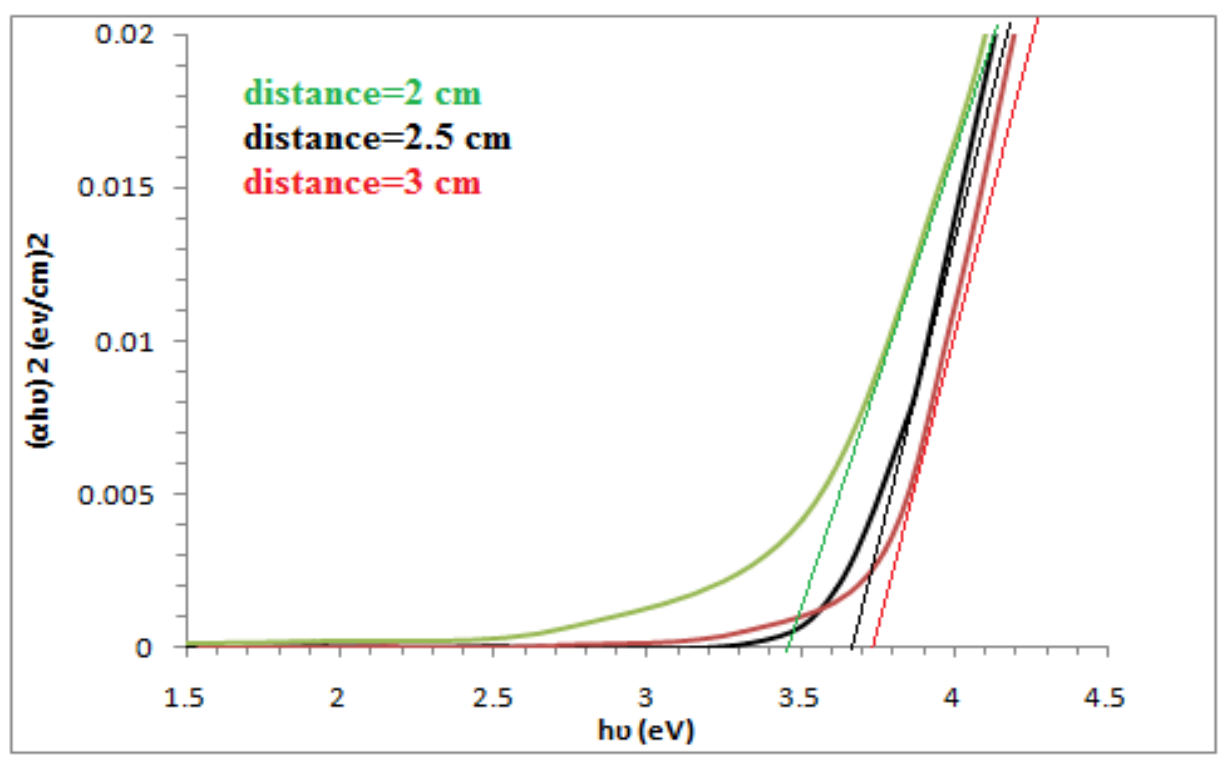

Fig.3: The variation of $(a h v)^{2}$ versus the Photon Energy (hv) of a-C: $H$ thin films thin film at the different distance between the substrate and plasma torch.

The scanning electron microscope analysis

In order to gain more insights of The morphological characteristics of the DLC films, SEM analyses of the DLC film surfaces under the influence of different distance between the quartz substrate and the end of the 
plasma torch are performed SEM image of DLC thin films prepared by atmospheric pressure plasma jet were shown in Fig.4. This figure illustrates the DLC nanoparticles at a different distance $(2,2.5,3 \mathrm{~cm})$ between the substrate and the plasma torch with an argon flow rate of $0.5 \mathrm{~L} / \mathrm{min}$. Also, this figure demonstrates that the average particles size decrease with increasing the distance. Figs.4 (a, b and c) illustrate the surface morphology of the carbon films with distance 2, 2.5 and $3 \mathrm{~cm}$, respectively. One can observe that the morphologies radically changed with the different distance where the nanoparticles become larger and rougher at a small distance as compared with the big distance between the quartz substrate and the end of the plasma torch, because of the accumulation of charges on carbon particles where the lower the distance the greater the accumulation of particles due to electrical forces.

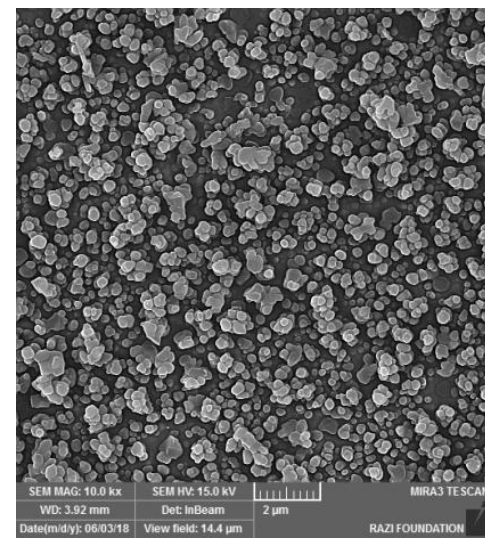

a

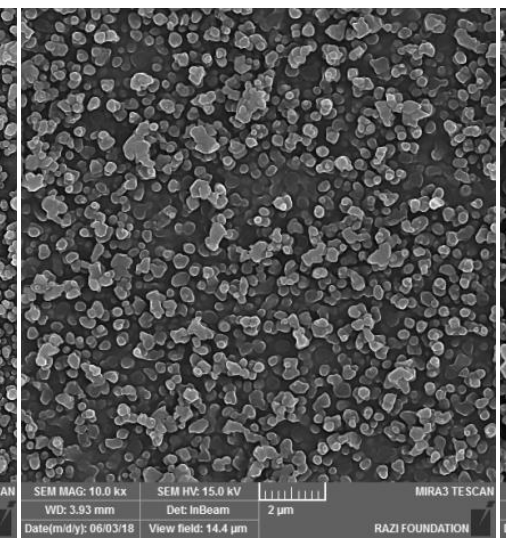

b

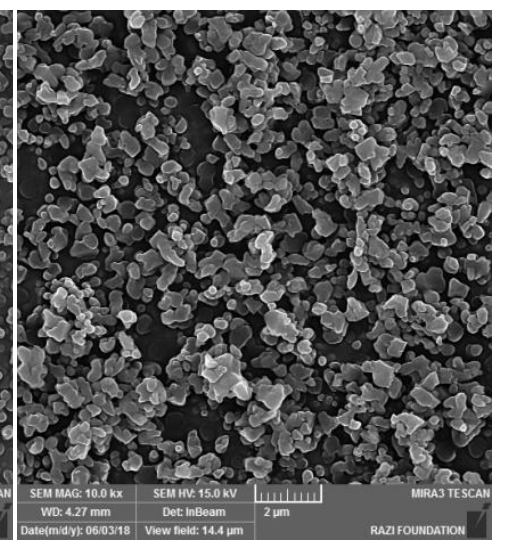

Fig .4 (a, b, c): SEM of the fractured surface of DLC thin films at the different distance between the quartz substrate and the end of the plasma torch, $a-2 \mathrm{~cm} . b-2.5 \mathrm{~cm} . c-3 \mathrm{~cm}$.

\section{X-ray diffraction patterns}

Figs.5 ( $a, b$ and $c$ ) show the x-ray diffraction pattern of the carbon films which prepared with Ar flow rate 0.5 $\mathrm{L} / \mathrm{min}$ and at different Distance between the substrate and the end of plasma get a torch $(2,2.5$ and $3 \mathrm{~cm}$, respectively). In fig.5a four diffraction peaks are found in the spectra at $2 \theta$ values Two of them at $2 \theta 26.56^{\circ}$ and $51.86^{\circ}$ which could be recognized with reflection form (002) and (102) plane of graphite and the peaks at $2 \theta 43.32^{\circ}$ and $73.93^{\circ}$ could be assigned to the (111) and (220) lattice spacing of cubic diamond. In fig. $5 \mathrm{~b}$ the sharp peaks at $2 \theta \quad 26.48^{\circ}, \quad 51.56^{\circ}$ could be a contribution to graphite (002) and
(102). High-intensity peaks are centred at $2 \theta 43.34^{\circ}, 73.86^{\circ}$ corresponding to the (111) and (220) diamond plane. The peaks for the hexagonal structure of graphite are located at $2 \theta 26.48^{\circ}$, $51.56^{\circ}$ in fig. $3 b$. While In fig. 5 c Two clear peaks can be seen at $43.44^{\circ}$, $73.90^{\circ}$ could be suggested to identified with reflections form (111) and (220) diamond plane. Fig .5b shows the highest intensity peaks which assigned to (111) and (220) diamond plane. The presence of diamond peaks with high intensity in the x-ray diffraction pattern for this sample indicates high content from $\mathrm{sp}^{3}$. This means more crystallization in this sample. 


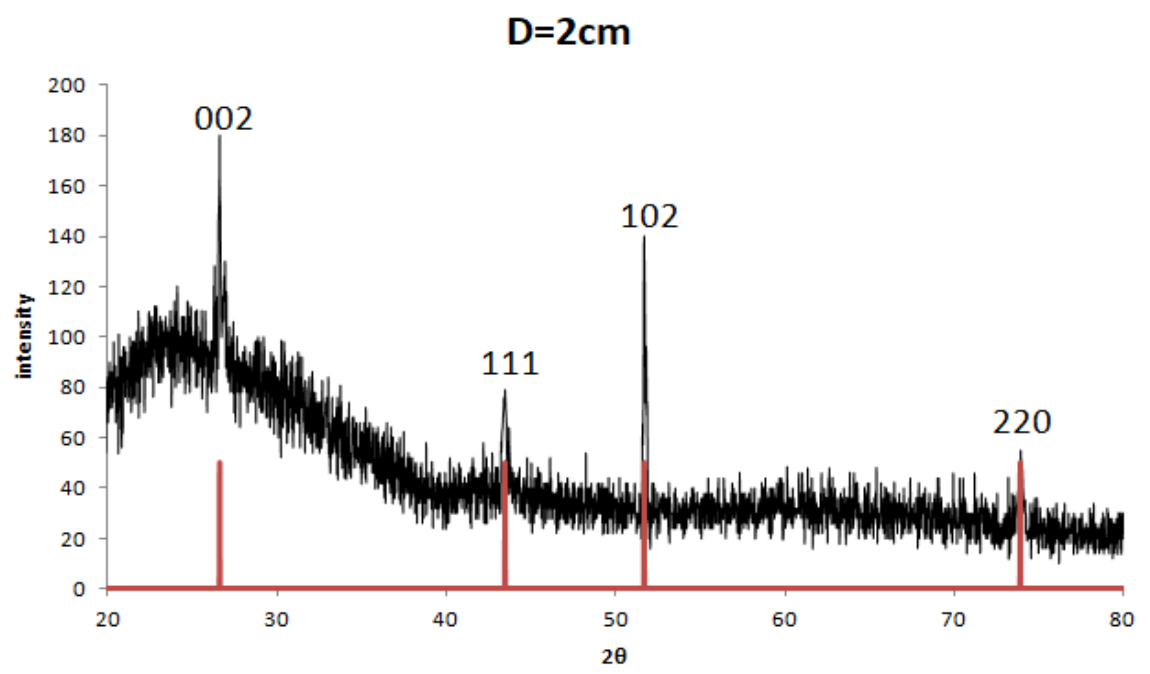

(a)

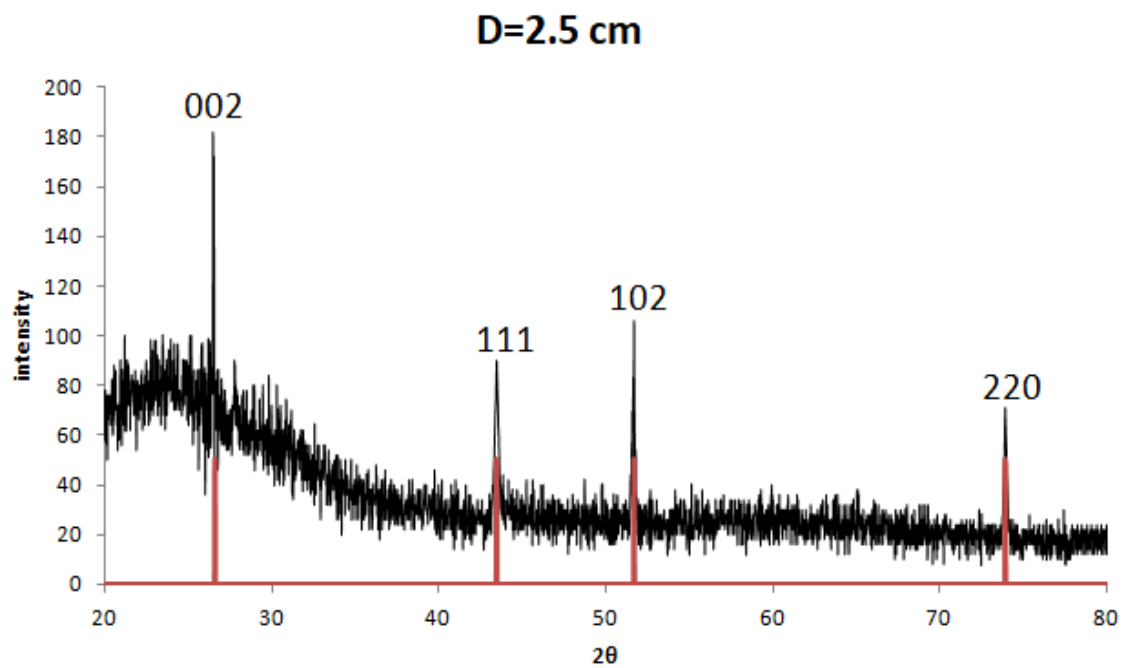

(b)

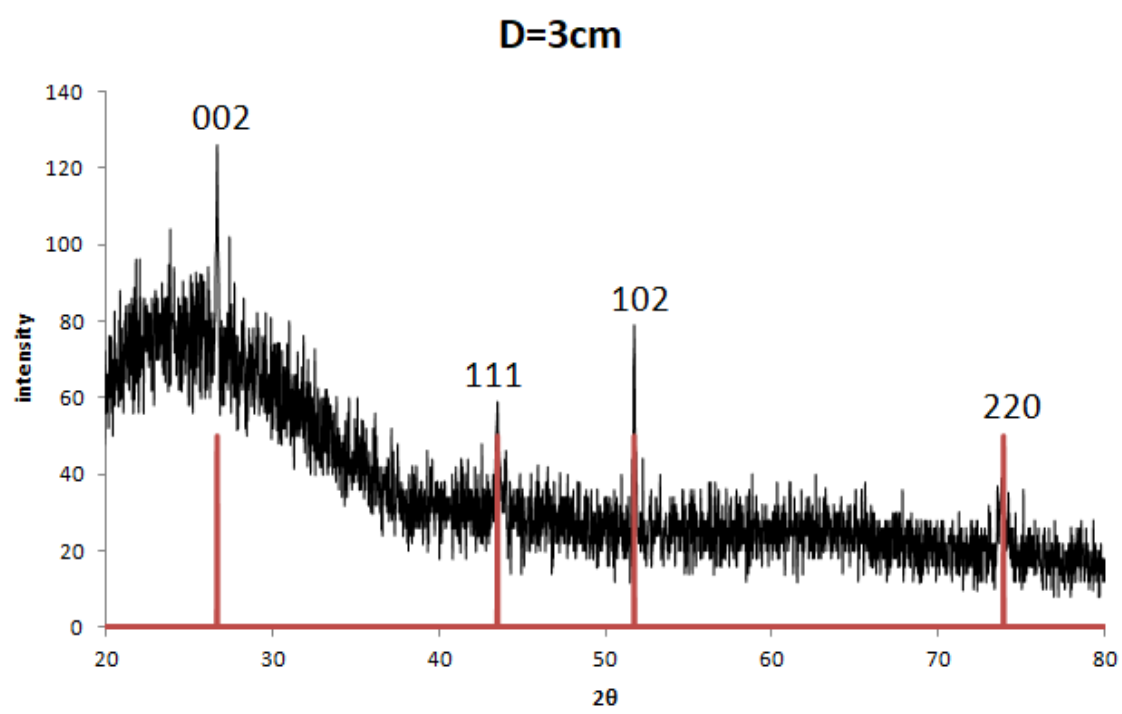

(c)

Fig.5: X-ray spectrum of DLC films at variable distance (a) $2 \mathrm{~cm}$, (b) $2.5 \mathrm{~cm},(\mathrm{c}) 3 \mathrm{~cm}$. 


\section{The FTIR analysis}

Figs .6 (a, b and c) demonstrates FT-IR spectra for DLC films deposited on the quartz substrate from cyclohexane by plasma jet at the various distance between the substrate and the plasma torch $2,2.5$ and $3 \mathrm{~cm}$, respectively with 0.5 flow rate of argon gas. The spectra in fig.6a demonstrate Peak at 2900 is of $\mathrm{C}-\mathrm{H} \quad\left(\mathrm{sp}^{3}\right)$ configuration and peak at 2875.67 are of $\mathrm{CH}_{2} \quad\left(\mathrm{sp}^{3}\right)$ configuration. The deformation peaks present of $\left(\mathrm{sp}^{3}\right) \mathrm{C}$ $\mathrm{CH}_{3}$ at1458.08 and1380.49 $\mathrm{cm}^{-1}$. The peaks from $1303.79 \mathrm{~cm}^{-1}$ to 1525.59 $\mathrm{cm}^{-1}$ having $\mathrm{C}-\mathrm{C}\left(\mathrm{sp}^{3}\right)$ configuration. The spectrum in Fig. 6 b the peaks at
2921.69, 2864.09 $\mathrm{cm}^{-1}$ correspond to the $\mathrm{CH} \quad\left(\mathrm{sp}^{3}\right)$ and $\mathrm{CH}_{2} \quad\left(\mathrm{sp}^{3}\right)$ respectively where the area under these peaks indicates the increase in the ratio. the deformation peaks of $\mathrm{C}-\mathrm{CH}_{3}$ $\left(\mathrm{sp}^{3}\right)$ at 1458.08 and $1375.15 \mathrm{~cm}^{-1}$.the peaks at the range from 1310 to $1539.09 \mathrm{~cm}^{-1}$ represent $\mathrm{C}-\mathrm{C}$ having sp $\mathrm{sp}^{2}$ and $\mathrm{sp}^{3}$ configuration. At the fig.6c, the peaks at 2931.60, $2883.38 \mathrm{~cm}^{-1}$ correspond to the $\mathrm{CH}\left(\mathrm{sp}^{3}\right)$ and $\mathrm{CH}_{2}$ $\left(\mathrm{sp}^{3}\right)$ respectively, the deformation peaks of $\left(\mathrm{sp}^{3}\right) \quad \mathrm{C}-\mathrm{CH}_{3}$ at 1461.94 and1311.5 $\mathrm{cm}^{-1}$. The absorption bands in the range 1300 to $1546 \mathrm{~cm}^{-1}$ represent $\mathrm{C}-\mathrm{C}$ having $\mathrm{sp}^{2}$ and $\mathrm{sp}^{3}$.

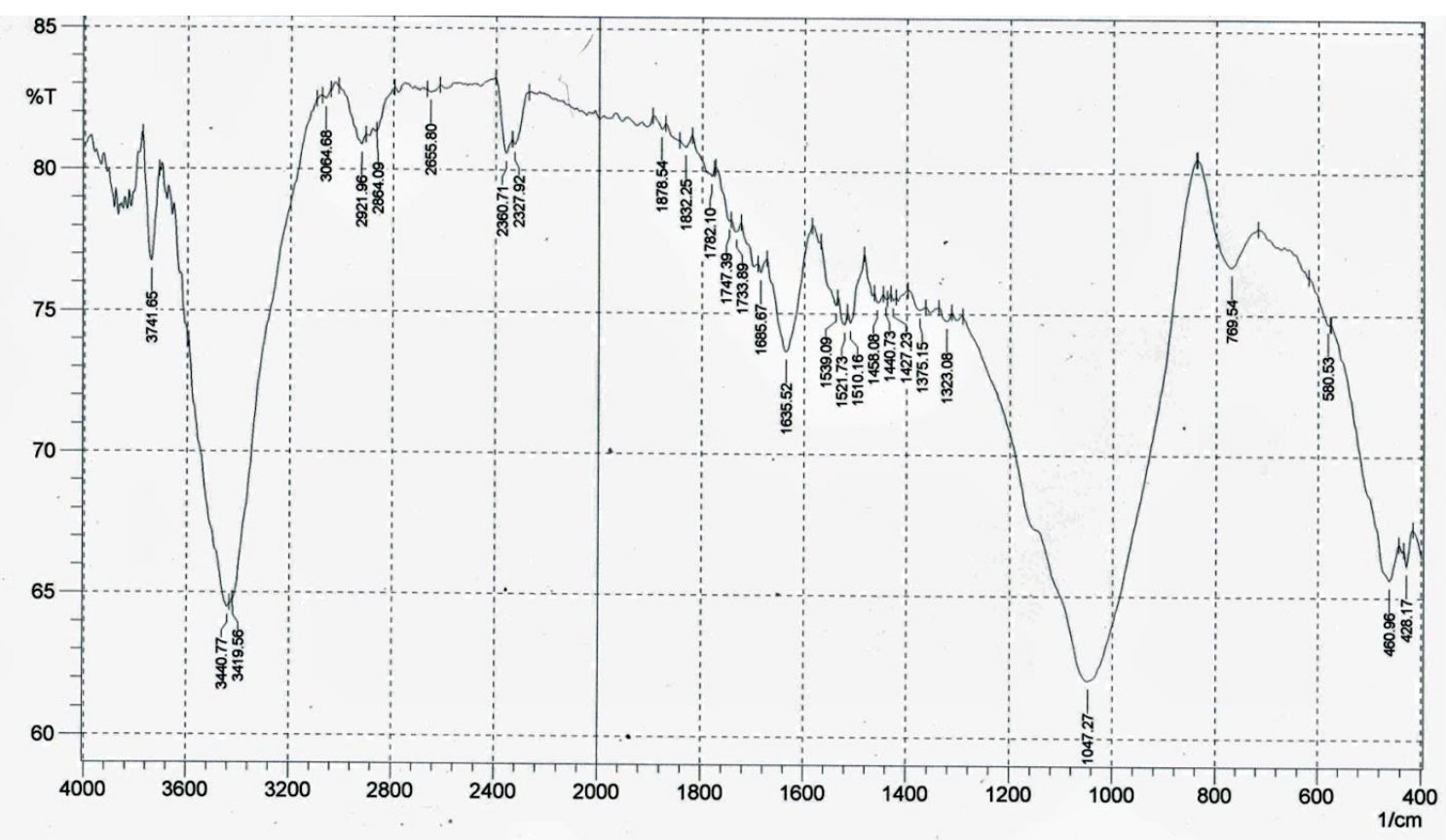

(a)

Fig. 6: Typical FTIR spectrum of DLC at a different distance between the substrate and the plasma torch a) $2 \mathrm{~cm}$. 


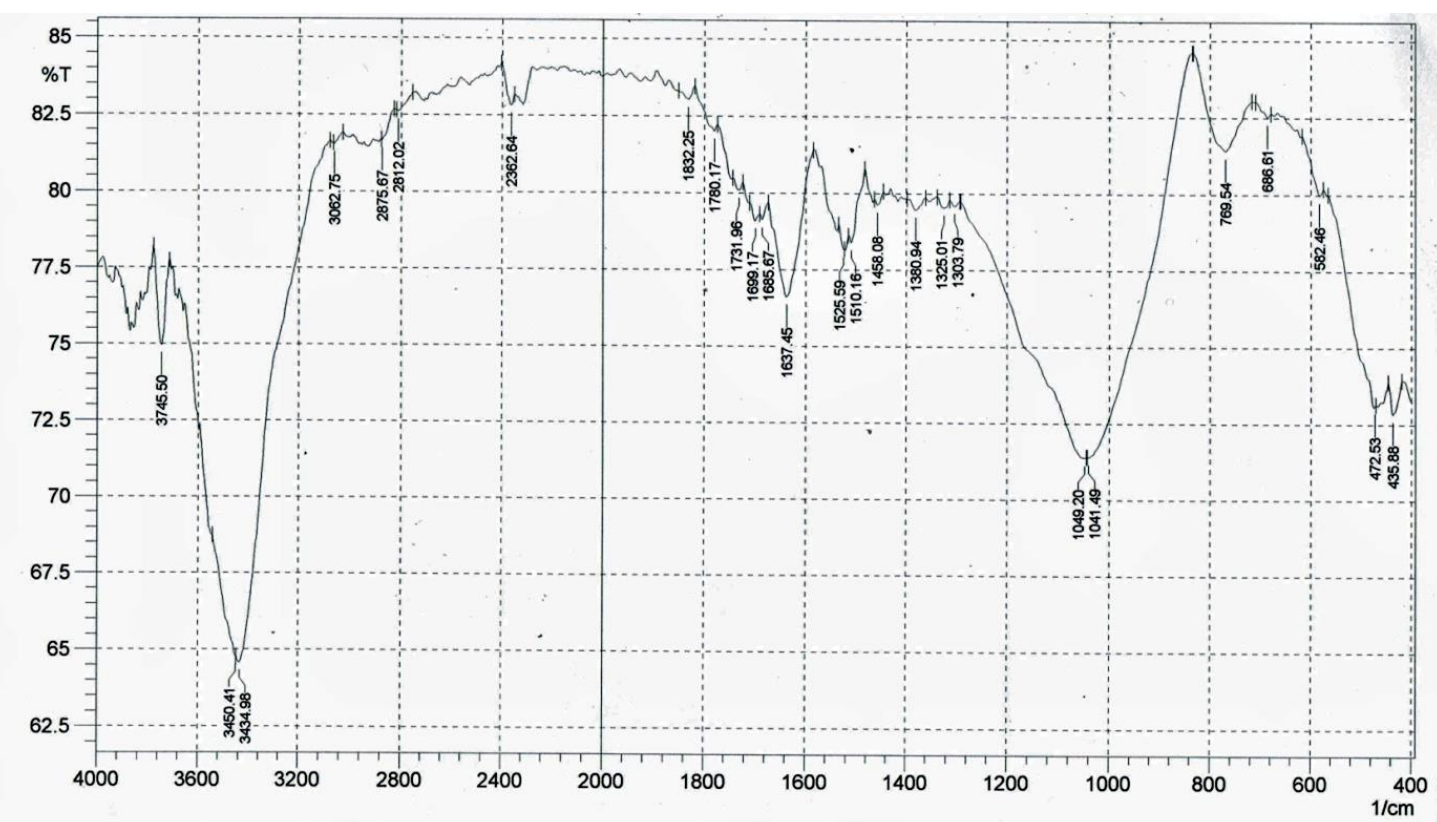

(b)

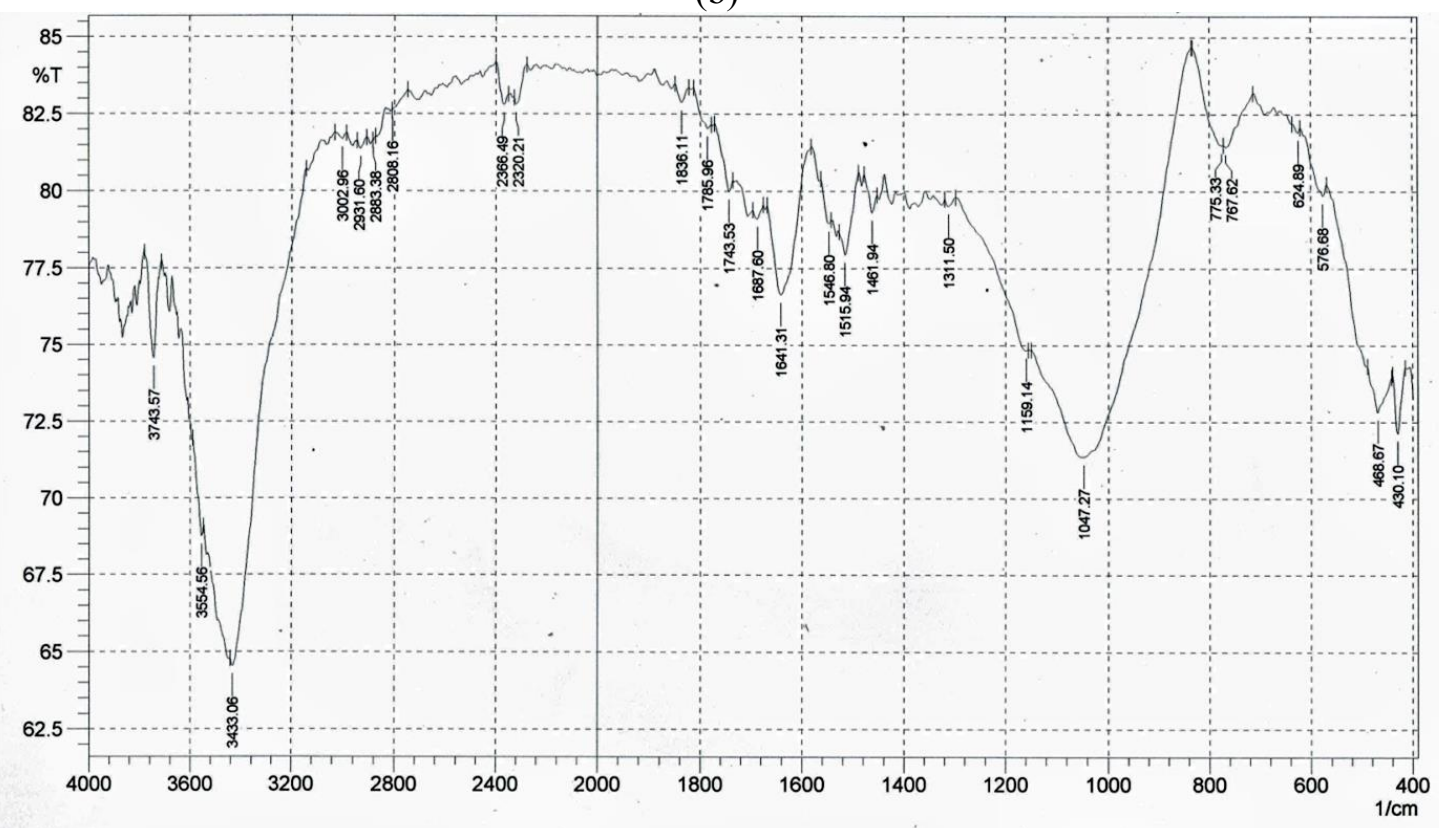

(c)

Fig. 6: Typical FTIR spectrum of DLC at a different distance between the substrate and the plasma torch b) 2.5 and c) $3 \mathrm{~cm}$.

\section{Conclusions}

Plasma jet can be used successfully to deposit the diamond-like carbon films. The significance of this research comes from the ability to alter optical properties and energy gap of DLC films by changing the distance between the substrate and plasma torch. The crystalline and nanoparticle size of DLC thin films can be controlled by altering the distance between the sample and the plasma source. SEM images show that the average particles size decrease with increasing the distance. The X-ray spectrum includes peaks for the crystalline structure of diamonds and others for graphite.

\section{References}

[1] K. Bewilogua and D. Hofmann, Surface and Coatings Technology, 242 (2014) 214-225. 
[2] V.G. Geidarov, I.S. Braude, N.N. Gal'tsov, Yu.M. Pohribnaya, Molecular Crystals and Liquid Crystals, 661, 1 (2018) 20-24.

[3] S. H. Yao, Yan Liang Su, Yu Chen Lai, Huang Ming Wu, Applied Mechanics and Materials, 883 (2018) 43-47.

[4] K. Bewilogua, D.Hofmann, Surface and Coatings Technology, 242 (2014) 214-225.

[5] J. Molina-Duarte, L.I.EspinosaVega, A. G. Rodríguez, R.A.GuiradoLópez, Physical Chemistry Chemical Physics, 19 (2017) 7215-7227.

[6] X. Sun, S. Zaric, D. Daranciang, K. Welsher, Y. Lu, X. Li, and H. Dai, J. Am. Chem. Soc., 130, 20 (2008) 65516555.

[7] A. Grill, Diamond and Related Materials, 12 (2003) 166-170.

[8] M. Zheng, A. Jagota, M. S. Strano, A. P. Santos, P. Barone, S. G. Chou, B. A. Diner, M. S. Dresselhaus, R.S. McLean, G.B. Onoa, G.G. Samsonidze, E.D. Semke, M. Usrey, D.J. Walls, Science, 302 (2003) 15451548.

[9] Robertson J. Hard amorphous (diamond-like) carbon. Prog Solid State Chem., 21 (1991) 199-333.
[10] X. B. Yan, T. Xu, S. R. Yang, H. W. Liu, Q. J. Xue, Journal of Physics D: Applied Physics, 37 (2004) 24162424.

[11] O.S. Panwar, Mohd. Alim Khan, Mahesh Kumar, Sonnada Math Shivaprasad, Bukinakere Satyarayana, P.N. Dixit, Raghunath Bhattacharyya, M. Y. Khan, Thin Solid Films, 516, 8 (2008) 2331-2340.

[12] E. Stoffels, A. J. Flikweert, W. W. Stoffels, G. M. W. Kroesen, Plasma Sources Sci. Technol, 11 (2002) 383-388.

[13] A. V. Pipa, S. Reuter, R. Foest, K-D Weltmann, Journal of Physics D: Applied Physics, 45, 8 (2012) 085201-1_085201-7.

[14] H. Jamali R, Mozafarinia, A. Eshaghi, Surface and Coatings Technology, 302 (2016) 107-116.

[15] Q. Wei, A. K. Sharma, J. Sankar, J. Narayan, Composites Part B: Engineering, 30, 7 (1999) 675-684.

[16] L. Eckortova, Physics of Thin Films Plenum Press, New York and London (1977). 